\title{
Deformation Analysis Due to Early Loading of Concrete Buildings
}

\author{
Romildo Alves Berenguer, Fernando Artur Nogueira Silva, João Luiz de Melo Ramos, Fabio Carneiro Lourenço, \\ Pryscylla Fernanda Silva Chaves and Ana Cecília Ferreira Leite \\ Department of Civil Engineering, Catholic University of Pernambuco, Recife 51110-200, Brazil
}

\begin{abstract}
The building industry has experienced in recent years a strong growth in demand in general and in the case of reinforced concrete buildings this increase has been more marked. This fact has also contributed to accelerate all stages of the production process of these constructions with more pronounced effects on the methodologies used in the constructive steps that influence directly the structural design of the building. Structures loaded at ever earlier ages, in which the strength and deformation properties of materials are not yet sufficiently mature. It is a variable that needs to be taken into account already in the design phase so that the concrete structure behaves within acceptable level of reliability taking into account design code recommendations for service life. To understand the importance of constructive effects and to assess its magnitude in the execution of reinforced concrete buildings, this paper presents result from nonlinear analyses using finite element method adopting an approach commonly referred as staged construction applied to a typical building found in the practice. The effects of creep and shrinkage were considered and the results obtained demonstrate that the strains due to constructive effects can, in certain cases, assume representative values which, if ignored, can lead to important pathologies in the building.
\end{abstract}

Key words: Reinforced concrete buildings, constructive effects, staged construction, creep, shrinkage.

\section{Introduction}

Nowadays there is a clear demand in the specific construction sector to build vertical multistory reinforced concrete buildings, in response to the growing population plus the restricted spaces in some areas worldwide. Together with the demand, there is also a need for fast constructions, thereby accelerating all stages in the production process of these buildings, with important effects on the construction stages, which directly influence the structural design phase.

This process creates the need to load the structure at an even earlier stage. The actions arising from the construction process in multistory buildings may consequently impact the building before the time determined in the structural design. Time alters the strength and deformability properties of the concrete [1], creating undesirable cracks that in turn diminish the rigidity of the cracked element, causing

Corresponding author: Romildo Alves Berenguer, professor, research fields: concrete, corrosion and materials. further deformations during the building's usable life.

Creep and shrinkage are effects depending on the time of the concrete, with increased speed in implementing the construction stages significantly influencing further deformation of the concrete structure in general, and therefore these effects must be considered in the design stage [2].

According to Prado [2], in the special case of the behavior of concrete structures in service conditions, another factor worth mentioning is the nonlinear analysis that adds the effects of the material's cracking (less rigidity) to the estimating of deformations and displacement of the structural elements. This analysis shows that there is a divergence in the stresses resultants on beams and columns in comparison with the usual linear analysis.

The paper discusses the importance of considering the effects of time, creep and shrinkage in the analysis and design of reinforced concrete multistory buildings. The subject is relevant because the implementation 
conditions deployed usually differ in practices adopted by the builders, in design, mainly with regard to dates for removing shoring, and in the guarantee of strength and deformability conditions recommended by designer. In fact, shoring is removed even earlier when the concrete has not yet reached suitable conditions and properties. In other words, it is not sufficiently "mature" to withstand the actions arising from the construction process deployed, and this procedure could cause excessive deformations that may compromise the structure's proper functioning.

\section{Construction Effect on Reinforced Concrete Buildings}

Loads that act during the construction of reinforced concrete multi-storey buildings are influenced by the techniques used and, in some situations, can affect building performance and contribute, in extremely cases, to overcome the load capacity of the construction considered in the design phase [3].

A large number of dead loads in concrete buildings acts on the structure during their implementation stage, at which time is not yet "mature" enough to withstand the applied load [4]. This implementation reality is increasingly frequent in the civil construction industry and it is necessary for the designer to consider this effect when adopting models and analytical processes of design.

Reinforced concrete building structures are sometimes analyzed considering the entire building to be implemented at a single time. Therefore, having obtained the applied forces by means of a certain analysis, the sections are designed in the ultimate limit state to be reached when increasing the actions and reducing the strengths of the materials involved [5]. This hypothesis is valid for vertical actions applied to the fully completed structure, but for actions, such as own self weight (dead load), which are gradually applied at various stages of construction, it does not represent the real implementation conditions. In this case, the effects arising from the different stages of the building's construction process must be considered in the design phase.

The construction in stages helps to define a sequence of construction phases, where parts of the structure can be added or removed and selectively applied loads on parts of it, as well as consider the behavior of the material over time, such as aging, deformation and shrinkage. Construction in stages is also known as incremental, segmental or sequential construction [2].

The procedure takes into account three types of analysis: linear, nonlinear without time effects and nonlinear with time effects (five years after the end of the construction), where the whole construction timetable was considered with gradual layering of floors. Therefore, the different construction stages are considered, all with strength and deformability characteristics of slabs, beams and pillars achieved through different methods varying with the type of analysis.

\section{Materials and Method}

In the analysis of construction effects, a 20-story reinforced concrete building with a simple structure was proposed. The layout of the stories consists of columns and beams with cross sections with dimensions of $20 \times 80 \mathrm{~cm}$ and $20 \times 60 \mathrm{~cm}$, respectively. Slabs have $15 \mathrm{~cm}$ in height.

Properties of concrete used in the analysis are performed as follows:

- compressive strength $-f_{c}: 30 \mathrm{MPa}$;

- elastic modulus-Ec: 26,991.77 MPa;

- unit weight: $25 \mathrm{kN} / \mathrm{m}^{3}$.

Fig. 1 shows the layout of the building's floor type analyzed, consisting of a model used solely for numerical analyses, not representing a real building. It was used to study in greater depth the strategies adopted in modeling the construction effect in the finite element program used.

The building was analyzed with and without considering the construction effect using linear and 


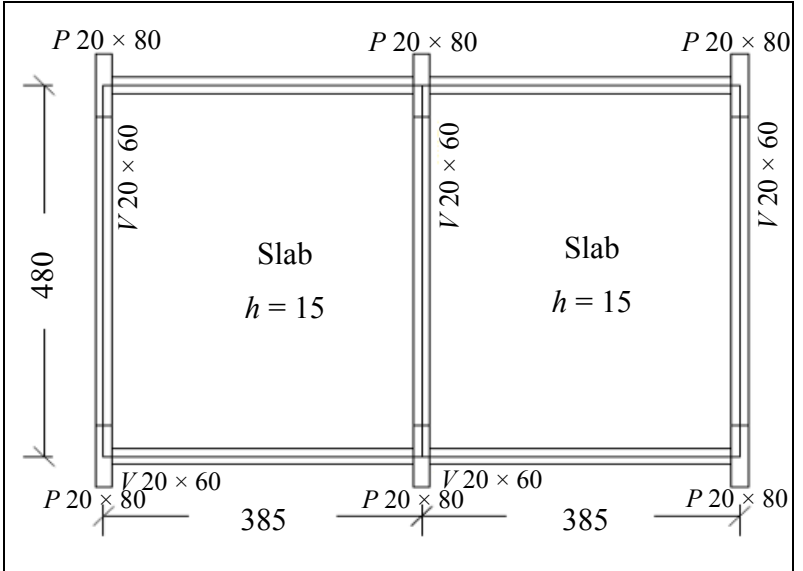

Fig. 1 Typical storey (unit in $\mathrm{cm}$ ).

nonlinear models using finite element method. A three-dimensional model was adopted with individualized discretization of columns and beams with bar elements and slabs with plate elements.

With non-linear analysis, one desires to take into account stages construction and model the behavior of the construction as close as possible the way of building.

To model the building in the nonlinear analysis 20 stages were considered, each stage corresponding to a story in the building. The duration of each stage was 14 days in order to represent usual construction situations of multistory reinforced concrete buildings in Brazil. Each load stage consists of concrete elements comprising each story of the building, namely beams, columns and slabs.

The resulting structure was analyzed solely for long-term permanent load condition (self-weight) that is directly related to the time effects on structural concrete. To consider the effects of time, the parameters of the concrete were as follows:

- $s$ (coefficient that depends on type of cement $)=$ 0.25 for concretes with Cement Types I and II;

- relative air humidity $=60 \%$;

- notional height $=30 \mathrm{~cm}$;

- shrinkage coefficient $=5$;

- age from start of shrinkage $=0$ day.

The above values were obtained from the CEB (Comité Euro-International $d u$ Béton)-90 expressions [6].

Fig. 2 illustrates the stress $x$ strain diagram for the concrete used in the models.

Fig. 3 exhibits a view of the finite element mesh used, that comprises 22,400 active degrees of freedom, with the representation of each storey of the building as a construction stage.

\section{Results and Discussion}

Results obtained with the three types of analyses performed (linear, non-linear without time effects and non-linear with time effects) are shown below.

Fig. 4 provides the vertical displacement values of the columns along the stages (floors).

It is noticeable that the linear analysis shows a

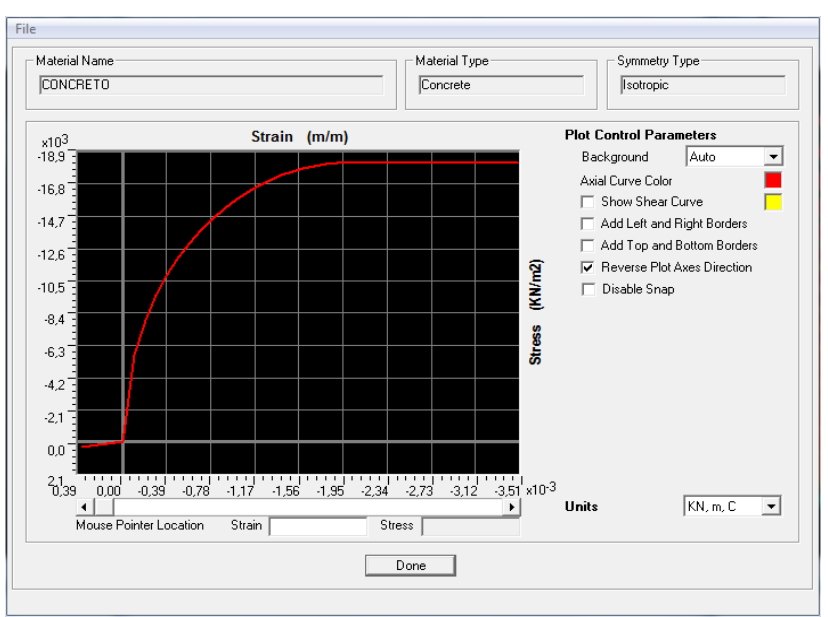

Fig. 2 Concrete stress $x$ strain diagram.

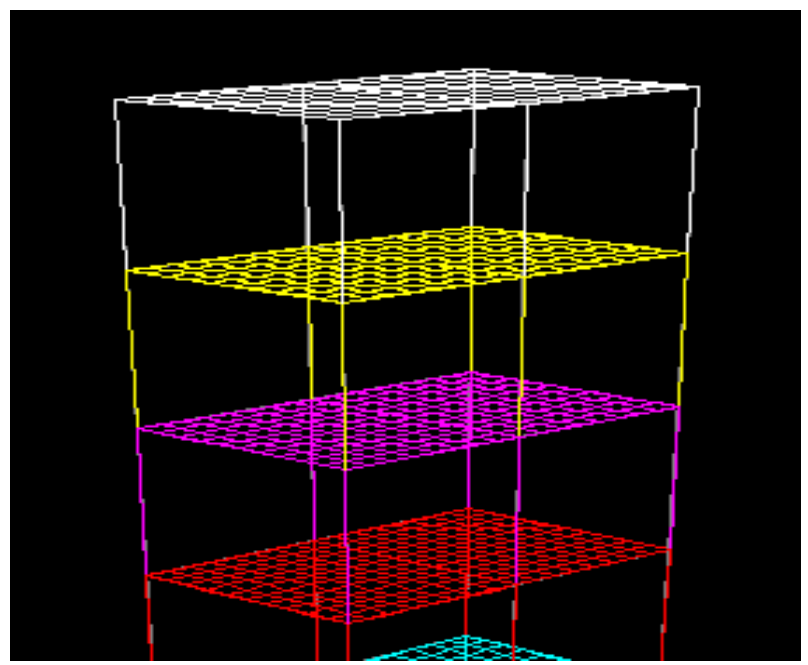

Fig. 3 Mesh used. 


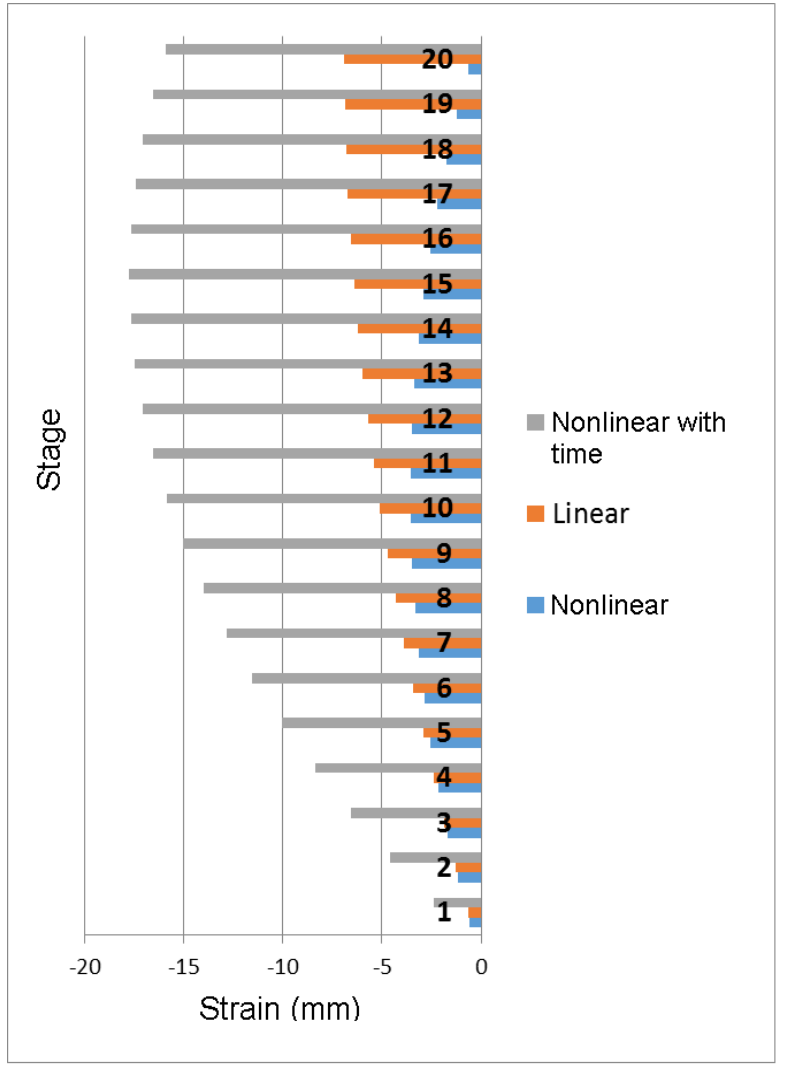

Fig. 4 Vertical displacements in the central column along the height of the building.

discrepancy compared with the nonlinear, that is, major differences, and that time considerably increases the deformation. Normally in designs of buildings, the stresses in the columns due to vertical loads have very different values, which leads to different axial deformations in these elements on each story. Considering this fact, an overall analysis of the structure accumulates on the upper floors non-existent vertical displacements. This causes the differential displacements between the points of the columns on the floors to increase along the height of the building, reaching maximum values at the top. This effect obviously leads to incorrect values of bending moments on beams and slabs connected to the columns.

Figs. 5-7 show the variation in the bending moment of a continuous beam during the stages. It was also analyzed three cross sections:

- the corner columns where it begins;

- the middle of the span;
- the central columns.

It is found that the bending moments of the linear analysis are greater than nonlinear analysis without time and nonlinear analysis with time. This is due to the accumulation of non-existent strain resulting a greater stress than those actually acting on the beams.

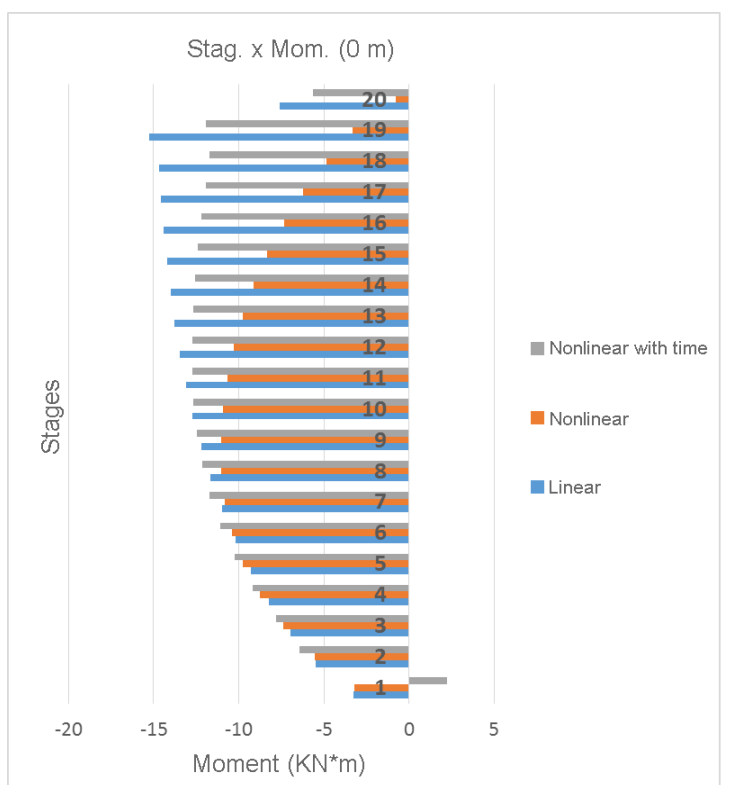

Fig. 5 Variation of the bending moment of an extreme support cross section of an external beam along the height of the building.

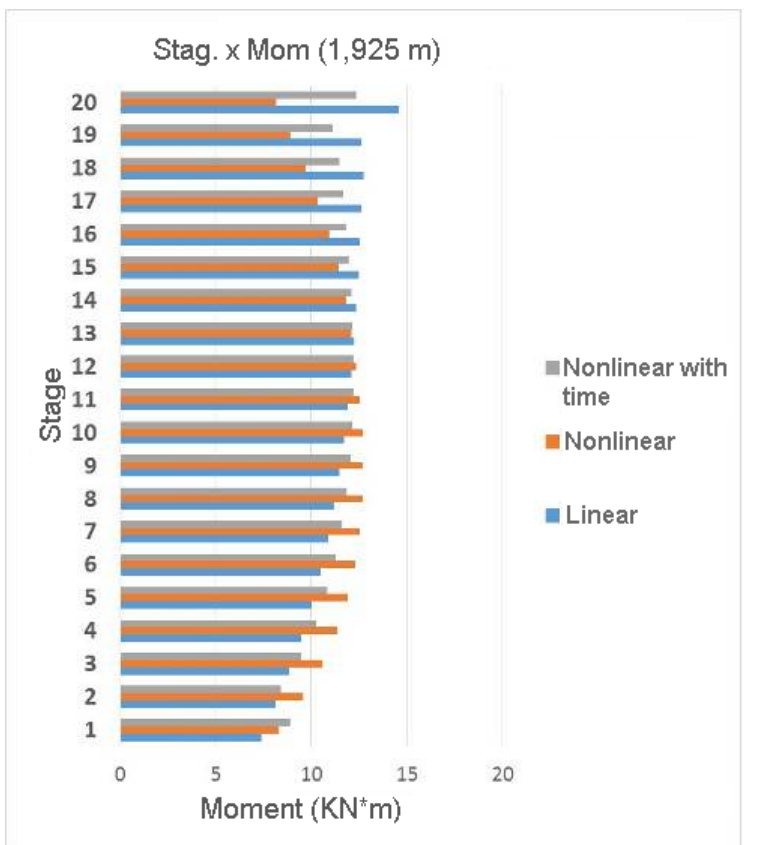

Fig. 6 Variation of the bending moment of a mid-span cross section of an external beam along the height of the building. 


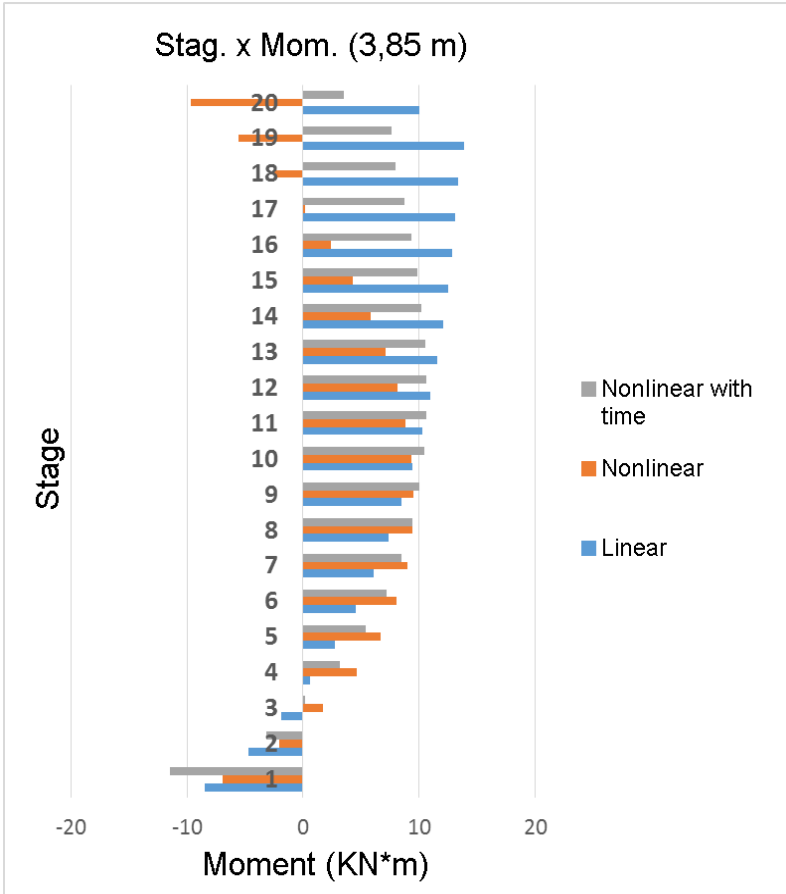

Fig. 7 Variation of the bending moment of a middle support cross section of an external beam along the height of the building.

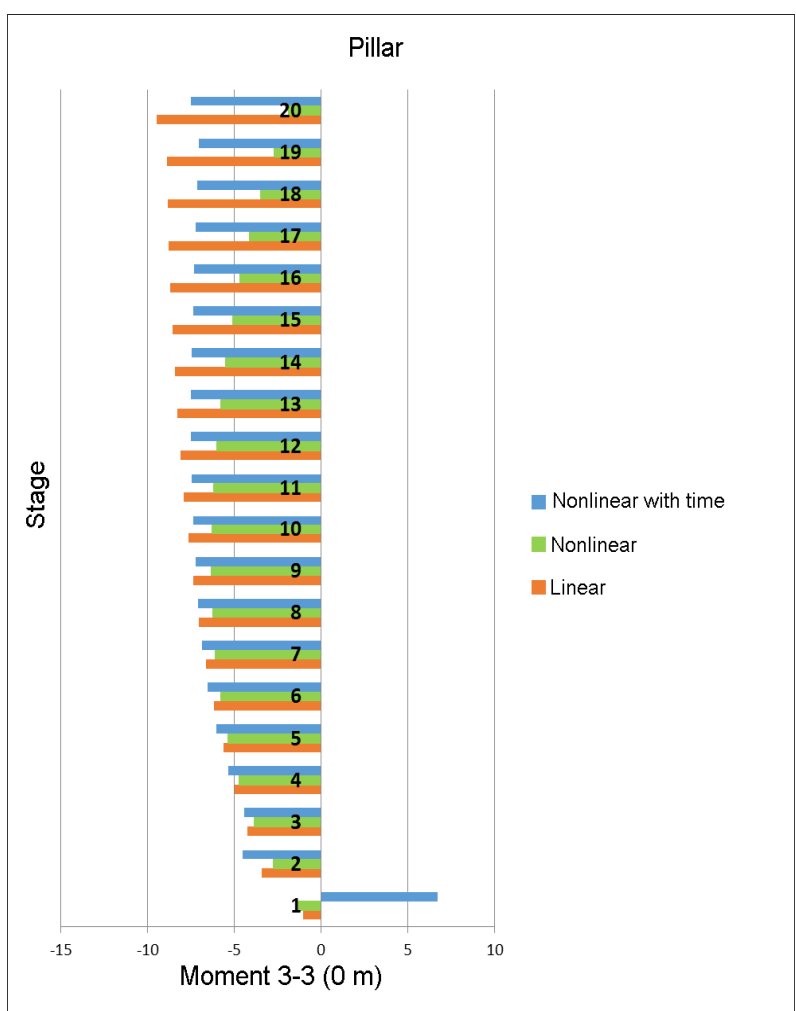

Fig. 8 Variation of bending moment in the base of a column along the height of the building.

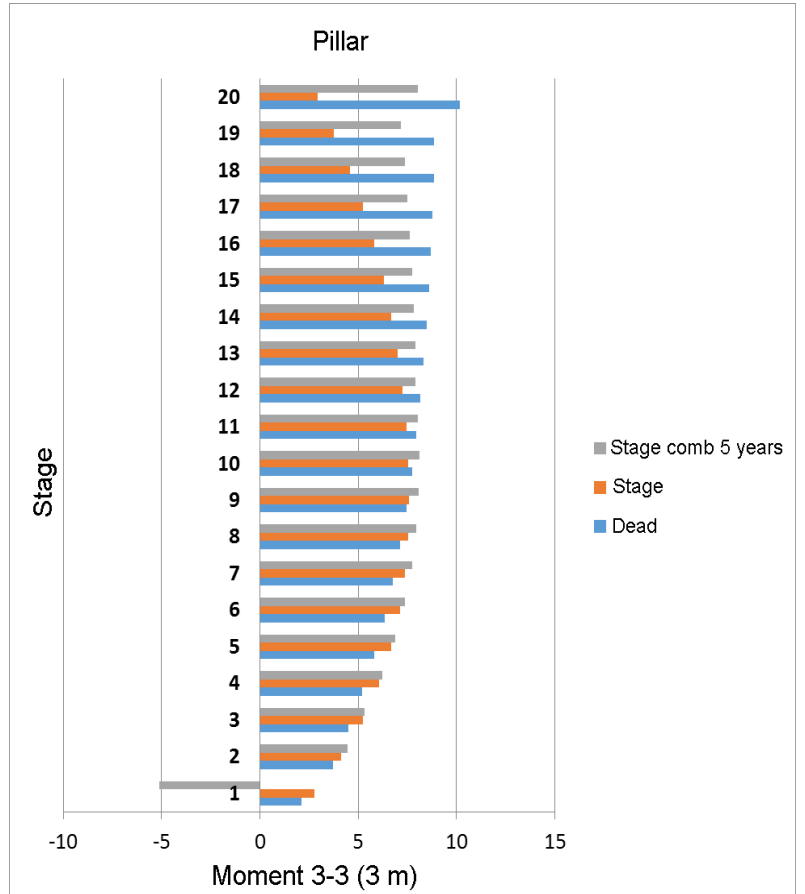

Fig. 9 Variation of bending moment at the top of a column along the height of the building.

This difference in stress reaches $60 \%$ compared to linear analysis and nonlinear analysis without the time.

Figs. 8 and 9 show the variations in force of the pillars on all floors.

Normally in building designs, the stresses in pillars due to vertical actions have very different values, leading to axial deformations differentiated in these elements on each story. Considering this fact, an overall analysis of the structure accumulates non-existing vertical displacements in the upper floors. This causes the different displacements between the points of a pillar on the stories to increase along the height of the building, reaching maximum values at the top as seen in Figs. 5-9. This effect obviously leads to incorrect values of bending moments in beams and slabs connected to the pillars [3].

\section{Conclusions}

The following conclusions can be based on the findings of the separate analyses: 
- The time affects the overall behavior of multistory reinforced concrete structures in a significant way. Vertical displacements, support reactions and stress resultants can change a lot if these effects is not considered;

- Values of the stress resultants from the linear analysis give a difference of around $60 \%$ compared to the time-effected nonlinear analysis;

- By analyzing the building in question, it can be concluded that, taking into account the fact of the load actions introduced in accordance with the building stages on molded structures during construction, values of applied forces and displacements on each story differ from those obtained traditionally, ignoring the stage construction (linear analysis).

\section{References}

[1] Araújo, J. M. 2010. Curso de Concreto Armado
(Reinforced Concrete Course). Vol. 1, 3rd ed. Rio Grande: Dunas. (in Portuguese)

[2] Prado, J. F. M. A. 1999. "Estruturas de Edifícios em Concreto Armado Submetidas a Ações de Construção (Reinforced Concrete Building Structures Undergoing Construction Actions)." Doctorate thesis, São Paulo University. (in Portuguese)

[3] Prado, J. F. M. A., and Correa, M. R. S. 2002. "Estruturas de Edifícios em Concreto Armado Submetidas a Ações de Construção (Reinforced Concrete Building Structures Undergoing Construction Actions)." Cadernos de Engenharia de Estruturas (Structural Engineering Notebooks) 19: 51-79. (in Portuguese)

[4] Chen, W. F., Rosowsky, D. V., and El-Shahhat, A. M. 1993. "Construction Safety of Multistory Concrete Buildings.” ACI Structural Journal 90 (4): 335-41.

[5] ABNT (Brazilian Association of Technical Standards). 2014. ABNT NBR-6118: Projeto de Estruturas de Concreto (Concrete Structural Design). Rio de Janeiro: ABNT. (in Portuguese)

[6] Comité Euro-International du Béton. 1993. CEB-FIP Model Code 1990. London: Thomas Telford. 